\title{
CHARACTERISTICS OF SUBCLONAL STRUCTURE IN THYROCYTE POPULATION IN RADIOIODINE- REFRACTORY METASTASES OF PAPILLARY THYROID CANCER
}

\author{
Anna Zelinskaya \\ State Institution " V. P. Komisarenko Institute of Endocrinology and Metabolism of the National \\ Academy of Medical Sciences of Ukraine", \\ 69 Vyshhorodska str., Kyiv, Ukraine, 04114 \\ ann.zelinskaya@ukr.net
}

\begin{abstract}
The aim of the study was cytological and immunocytochemical researches of thyrocyte populations in fine-needle aspiration smears of radioiodine-refractory metastases and their comparison with radioiodine-avid metastases and corresponding primary papillary carcinoma of the thyroid.

Materials and Methods. The cytomorphological and immunocytochemical researches were conducted on the fine needle aspiration smears of 60 papillary thyroid carcinomas and 104 metastases, which were detected in the postoperative period. We applied the indirect immunoperoxidase technique using primary monoclonal mouse antibodies against leukocyte-common antigen, macrophage antigen, thyroglobulin, epithelial cell adhesion molecule, cytokeratines 7.8, polyclonal rabbit antibodies against calcitonin.

Results. It was demonstrated, that radioiodine-avid metastases and corresponding primary papillary thyroid carcinoma smears had first type of cellular population with a relatively regular location of thyrocytes. Unlike them, radioiodine-refractory metastases smears had the second type of cellular population with irregularly location of thyrocytes among which showed up two cellular phenotypes. In our investigated smears some special cellular complexes were found - in $21 \%$ of radioiodine-refractory metastases, $1 \%$ in radioiodine-avid metastases and none of it in corresponding primary papillary thyroid. The cytological sign of cystic degeneration was found in $58 \%$ of radioiodine-refractory metastases, but in radioiodine-avid metastases - was absent.

Conclusion. The radioiodine-refractory metastases of papillary thyroid cancer demonstrated their distinction from radioiodine-uptake metastases with a presence of phenotypic heterogeneity. It is shown, that an appearance of certain cell subpopulations, special cellular complexes and cystic degeneration in fine-needle aspiration smears of radioiodine-refractory metastases, which in radioiodine-uptake metastases and corresponding primary papillary thyroid carcinomas were not found, can be used during the preoperative period to forecast the impossibility of radioiodine treatment.
\end{abstract}

Keywords: papillary thyroid carcinoma, fine-needle aspiration punction biopsy, radioiodine-refractory metastases, phenotypic heterogeneity of thyrocytes, subpopulations.

\section{Introduction}

Applying of radioiodine therapy, which is based on the ability of follicular epithelium to accumulate radioiodine (RI), underlies the advantageous prognosis of differentiated thyroid cancer (DTC) $[1,2]$. Unfortunately, 5-20\% of patients with DTC have metastatic radioiodine-refractory disease and the radioiodine therapy become ineffective for them, due to the fact that thyrocytes have lost their ability to accumulate radioiodine [3, 4]. Different authors have detected the correlation between a development of radioiodine refractoriness and a significant decrease of the survival median [5]. The data regarding a tumors' resistance to a commonly used therapy has shown that the clonal tumor heterogeneity may be based on its development $[6,7]$. Both theories of oncogenesis (stochastic theory of clonal evolution and cancer stem cell hypothesis) indicate that the monoclonal population of malignant tumor cells breaks down into a number of subclones and becomes phenotypically heterogeneous because of genetic and epigenetic changes $[8,9]$. This may have a clinical implication for the disease's progress and tumor therapy [10]. Cells that have lost their ability to accumulate radioiodine can be amongst those subclones that were mentioned. Therefore, the detection of cellular phenotypes that are associated with radioiodine refractoriness is of current interest to examination of the thyrocyte population in radioiodine-refractory metastases (RIRM) of papil- 
lary thyroid carcinoma (PTC). Farther, the available data has no information about subclonal structure investigation in fine-needle aspiration (FNA) smears. There was a demonstration of population heterogeneity in follicular epithelium on the histological sections of the thyroid nodule's tissue [11]. In addition, Mitsutake N. et al have done their in vitro researches of anaplastic thyroid carcinoma's cultures and showed a small subpopulation of cells that have a stem cell attribute [12]. Accordingly, the aim of the study was cytological and immunocytochemical researches of thyrocyte populations in FNA smears of RIRM and their comparison with radioiodine-avid (RIAM) and corresponding primary PTC (PPTC) of the thyroid.

\section{Materials and methods of research}

Investigated groups included FNA smears of 60 PTC and 104 metastases that were found during the sonographic and scintigraphic examination after thyroidectomy and RI - therapy, i. e. postoperative period. The specimens were obtained from patients who were examined, diagnosed with tumor and underwent thyroid surgery in the Institute of Endocrinology and Metabolism. The patients were both women (120) and man (44), also they were 26-79 years old.

PTC metastases that were identified by neck sonography after treating patients with $100 \mathrm{mCi}$ RI, but not detected by whole body scintigraphy were considered as RI-refractory (RIRM) ones. In contrast, PTC metastases that were found by scintigraphy after similar treatment were regarded as RI-avid (RIAM) ones. We have analyzed FNA smears of 79 RI-refractory and 25 RI-avid PTC metastases. FNA of thyroid and metastases was performed under ultrasound guidance using a 21-gauge needle, usually without a syringe or suction. Dried FNA smears were fixed for 5 minutes in methanol, followed by staining in Giemsa dye, diluted in $0.067 \mathrm{M}$ phosphate buffer ( $\mathrm{pH} 6.4$ ) for 30 minutes.

Immunocytochemistry was performed on representative Giemsa-stained smears after they were analyzed cytomorphologically. We've developed a method, which helps to unmasked antigens [13]. To identify certain antigens, we applied the indirect immunoperoxidase technique using primary monoclonal mouse antibodies against leukocyte-common antigen (CD45) (dilution 1:50, clone PD7/26 and 2B11, Dako, Denmark), macrophage antigen (CD68) (dilution 1:50, clone EBM11, Dako, Denmark), thyroglobulin (Tg) (dilution 1:100, clone DAK-Tg6, Dako, Denmark), epithelial cell adhesion molecule (epCAM) (dilution 1:100, clone Ber-Ep4, Dako, Denmark) as well as a number of cytokeratines (CK), namely CK7 (dilution 1:50, clone OV-TL 12/30, Dako, Denmark), CK8 (dilution 1:100; clone M20, Sigma, USA). Polyclonal rabbit antibodies were used to identify calcitonin (dilution 1:100, DBS, USA). Polyclonal rabbit anti-mouse immunoglobulins/HRP (dilution 1:100, Dako, Denmark) and goat anti-rabbit immunoglobulins/ HRP (dilution 1:100, Dako, Denmark) were applied as enzyme-labeled secondary antibodies. 3,3-diaminobenzidine tetrahydrochloride (Sigma, USA) was used as a chromogen. Endogenous peroxidase was inactivated by incubation in $1 \% \mathrm{H}_{2} \mathrm{O}_{2}$ in phosphate buffer $(\mathrm{pH}$ 7.4) at the room temperature for 30 minutes. Statistic analysis was performed via the non-parametric criterion $\chi^{2}$ in the package Statistica 11.0.

\section{Results and discussion}

The comparative cytological and immunocytochemical research of thyrocyte populations on smears of RIRM, RIAM and corresponding PPTC demonstrated the phenotypic heterogeneity in RIRM epithelium and its absence in the rest of the groups. RIAM and corresponding PPTC smears had the first type of cellular population, which comprised small epithelial cells (12-20 microns) with moderate nuclear-cytoplasmic ratios that had amphophilic or faintly oxyphilic cytoplasm. Also, they formed a single-layered formation with a relatively regular location of thyrocytes (Fig. 1).

Such thyrocytes featured the bright antibody reactions - cytokeratin 7 and 8 , thyroglobulin, epithelial cell adhesion molecules (epCAM) (Fig. 2).

However, RIRM smears had the second type of cellular population, which comprised enlarged polymorphic basophilic cells (24-48 microns) that had a reduced nuclear-cytoplasmic ratio. Thyrocytes were located irregularly among this type of cells (Fig. 3). 


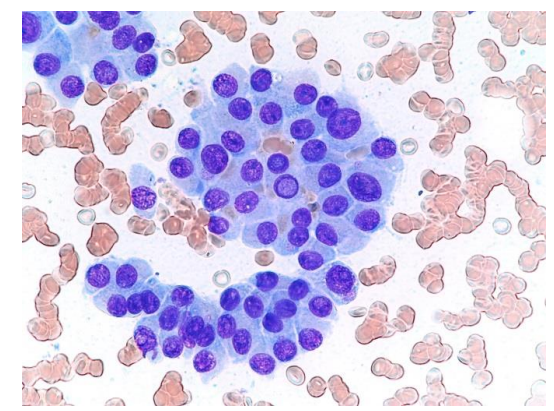

Fig. 1. The first type of cellular population with regular location of homogeneous, small thyrocytes in FNA smear of RIAM. $\times 400$

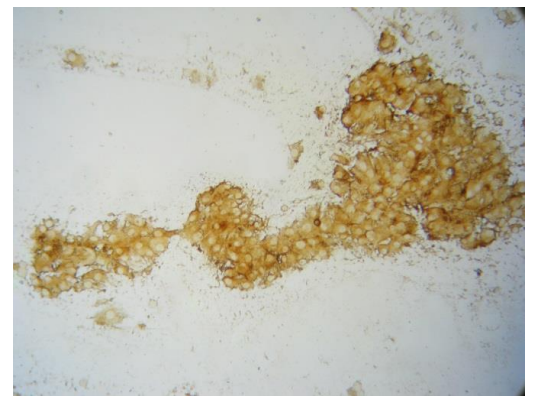

Fig. 2. Intensive immunocytochemical reactions with antibodies to thyroglobulin on each thyrocyte in FNA smear of RIAM of PTC. $\times 200$

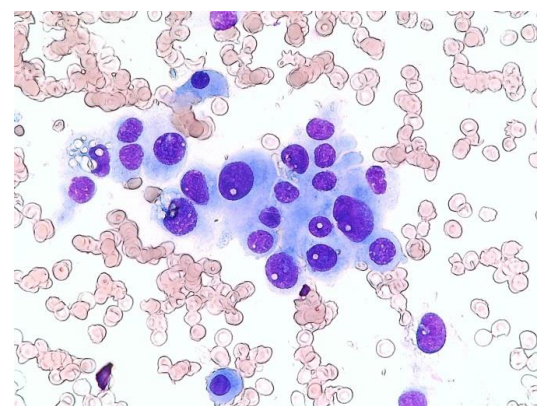

Fig. 3. The second type of cellular population with irregular location of polymorphic thyrocytes in FNA smear of RIRM of PTC. $\times 400$

The immunocytochemical reaction with antibodies to thyroglobulin had a mosaic appearance on these cellular populations (Fig. 4).

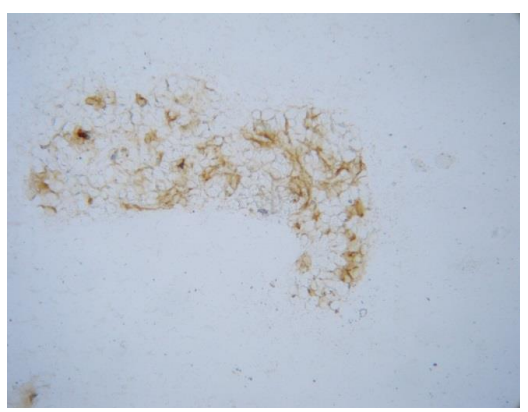

Fig. 4. A mosaic immunocytochemical reaction with antibodies to thyroglobulin on thyrocytes in FNA smear of RIRM of PTC. $\times 200$

Among the second type of cellular population showed up two cellular phenotypes. The first phenotype differentiated with their surface condition, clear-cut edges, round or pear shape, 
small nuclear-cytoplasmic ratio and diversified proportions (18-40 microns). Their cytoplasm had a moderate basophilia in a central area and had no stain on the periphery, thus they looked lighter among the other epithelial cells. Contingently, we called them cells of "S" subpopulation (Fig. 5).

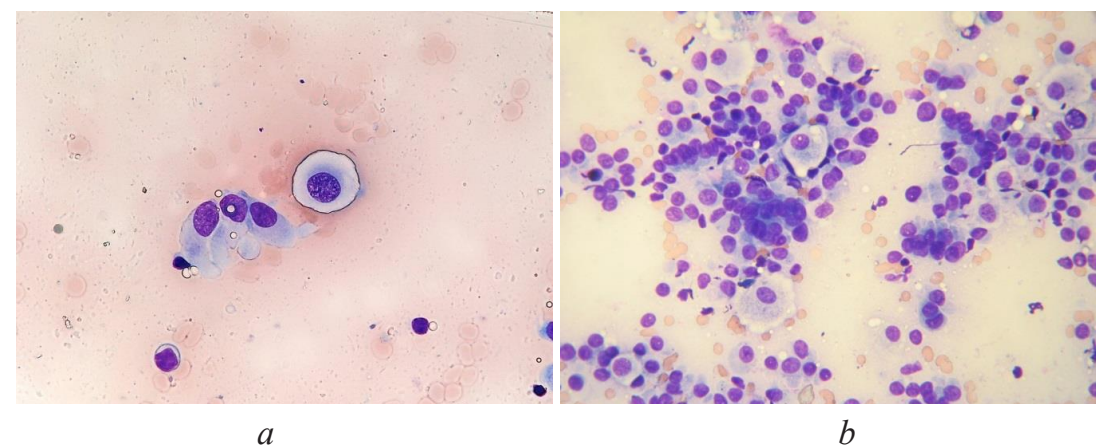

Fig. 5. "S" cells in FNA smear of RIRM of PTC: $a$ - "S" cell with clear-cut edges; $b-$ "S" cells among other thyrocytes. $\times 400$

The immunocytochemical investigations have shown that " $\mathrm{S}$ " cells do not comprise a leukocyte common antigen (CD45) and a macrophage marker (CD68), despite their resemblance to macrophages. Their positive antibody reaction to cytokeratins 7 and 8 instantiates an epithelial nature. "S" cells between times bind antibodies against cytokeratin 17, expression of which constantly occurs in PTC [14]. Meanwhile, "S" cells do not react with antibodies against epCAM, notwithstanding, this antigen always belong to all the epithelial thyrocytes (as a normal and with malignancy). Furthermore, "S" cells did not give a precise reaction to antibodies against thyroglobulin and did not comprise calcitonin, which excludes their relation to parafollicular cells.

A distinctive feature of the second phenotype was a round basophilic macula (diameter 4.5-18 $\mu \mathrm{m}$ ) in the cytoplasm near the nucleus. After the RNase influence, this macula did not stain with azure, which testifies that it consists of RNA. Contingently, we called them cells of "M" subpopulation. In contradistinction to "S" cells, they did not have clear-cut edges, insofar as their surface did not differ from other thyrocytes in expressive refraction (Fig. 6).

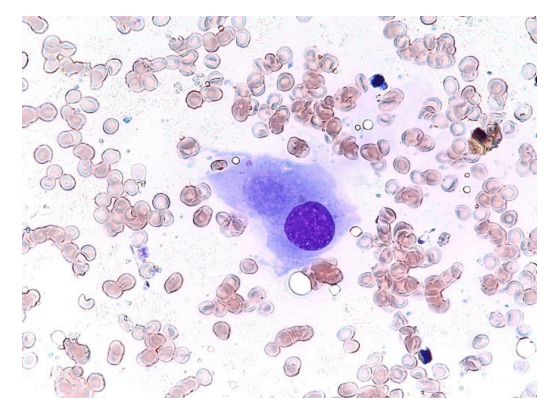

Fig. 6. "M" cell (macula-containing cell) in FNA smear of RIRM of PTC. $\times 400$

The immunocytochemical investigations have shown that "M" cells do not comprise CD45 and CD68 and have positive reaction with antibodies to cytokeratins 7 and 8, which justify their epithelial nature. As well as "S" cells, "M" cells do not have calcitonin. However, unlike "S" cells, "M" cells have thyroglobulin. Their antibody reaction against epCAM differs from other thyrocytes - expression is absent or has a temper by the way of the laminar structure between the contacting surfaces of "M" cells.

"S" cells were found in $31 \%$, "M" cells - in $30 \%$ of the investigated RIRM PTC and were absent in all investigated RIAM. "M" cells were found in $35 \%$ of corresponding PPTC, but "S" cells were absent there.

Moreover, some special cellular complexes were found in our investigated smears - in $21 \%$ of RIRM, 1 \% in RIAM and none of it in corresponding PPTC (Fig. 7). 


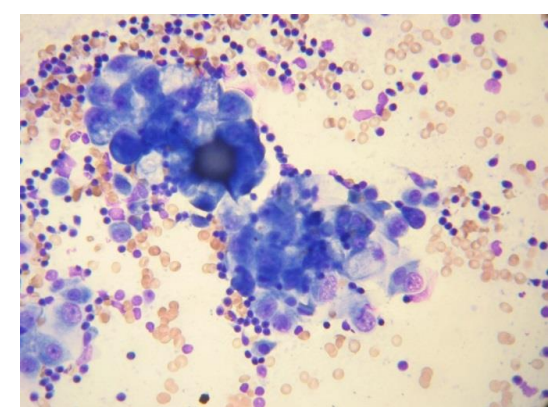

Fig. 7. Special complex of psammous body and vacuolated cells in FNA smear of RIRM of PTC. $\times 400$

These complexes consist of centrally located psammous body, surrounded by a layer of macrophages and vacuolated epithelial cells, most of which have cytokeratin 17 . We have demonstrated that this cytokeratin represents as a preoperative marker for radioiodine refractoriness of thyroid cancer [14].

The cytological sign of cystic degeneration (cystic fluid with macrophages) was found in $58 \%$ of RIRM, but in RIAM - was absent. In overall group of metastases of PTC, cystic degeneration was revealed only in $23 \%$ of cases.

In this way, the comparative cytological and immunocytochemical researches in the thyrocyte population structure of RIRM, RIAM and corresponding PPTC have demonstrated the phenotypic heterogeneity in RIRM, which appeared in the form of various cellular phenotypes, specific cellular complexes and cystic degeneration (Table 1).

Table 1

The frequency of various cytological signs in FNA smears of RIRM and RIAM PTC

\begin{tabular}{|c|c|c|}
\hline Cytological signs & RIRM (79) & RIAM (25) \\
\hline The first type of cellular population & $50(79) 63.2 \%$ & $100 \%$ \\
\hline The second type of cellular population & $37(79) 46.8 \%$ & $0 \%$ \\
\hline "S"-cells & $25(79) 31 \% *$ & $0 \%$ \\
\hline "M"-cells & $24(79) 30 \% *$ & $0 \%$ \\
\hline “S”+“M"-cells & $8(79) 10 \%$ & $0 \%$ \\
\hline Cystic degeneration & $35(79) 44 \% *$ & $1(25) 1 \%$ \\
\hline Complexes of psammous body and thyrocytes & $17(79) 21 \% *$ & $0 \%$ \\
\hline Cellular oxifilia & $10(79) \mathbf{1 2 . 6} \%$ & $1(25) 1 \%$ \\
\hline
\end{tabular}

Note: $*-p<0.05$

The presence of different subclones and thyrocyte complexes in FNA smears of RIRM PTC in comparison with RIUM, perhaps, is a demonstration of their genetic heterogeneity, which is a "firing field" for appearance of thyrocyte subclones that can predetermine the progress of radioiodine refractoriness. The immunocytochemical researches demonstrated that " $\mathrm{S}$ " cells have no thyroglobulin, which is relevant to the radioiodine accumulation. Besides, " $\mathrm{S}$ " and " $\mathrm{M}$ " cells have off-balanced expression and spreading of epCAM on the cytoplasmic surface. As known, these molecules are considered to be one of the crucial factors in epithelial-mysenchymal transition when epithelial cells lose their polarity, intercellular adhesion and attain the migration ability [15]. Perhaps, these characteristics of the cellular phenotype in explored metastases are a source of radioiodine refractoriness.

The study of cellular phenotypes in epithelium of PTC and its metastases is a latter-day cytological approach, not particularly their cytological and immunocytochemical signs. This ap- 
proach allows scrutinizing the correlation between radioiodine refractoriness and aggressive behavior of PTC with not only individual cellular characteristics, but with the complex of cytological and immunocytochemical characteristics that are associated with different cellular subpopulation (or phenotypes).

Since the phenotypic heterogeneity of thyrocyte population (presence of different subpopulations and cellular complexes) as a cytological characterstic is found in smears of RIRM PTC and not in RIAM, thereat its appearance can be considered as a cytological factor in radioiodine refractoriness prognosis for postoperative metastases of PTC. So, thanks to conducted researches it is possible to predict during preoperative period the behavior of metastases that were detected after thyroidectomy and radioiodine therapy and to determine an adequate tactic of treatment (further radioiodine therapy or surgical removal of metastases).

\section{Conclusions}

1. The subclonal structure in the population of metastases of PTC that were found during the postoperative period (RIRM and RIAM), for the first time ever, was investigated on FNA smears with cytomorphological and immunocytochemical researches.

2. It was demonstrated, that RIRM PTC differs from RIAM in phenotypic heterogeneity. It has been proved, that an appearance of certain cellular subpopulation, which are absent in PPTC and RIUM, but occur in RIRM, can be used for the preoperative prognosis of refractoriness to radioiodine therapy.

3. The phenotypic heterogeneity research in thyrocyte population of PTC is a latter-day and effective route in developing the methods of prognosis for metastases that has radioiodine refractoriness.

\section{References}

[1] Markovina, S., Grigsby, P. W., Schwarz, J. K., DeWees, T., Moley, J. F., Siegel, B. A., Perkins, S. M. (2014). Treatment Approach, Surveillance, and Outcome of Well-Differentiated Thyroid Cancer in Childhood and Adolescence. Thyroid, 24 (7), 1121-1126. doi: http://doi.org/10.1089/thy.2013.0297

[2] Haugen, B. R., Alexander, E. K., Bible, K. C., Doherty, G. M., Mandel, S. J., Nikiforov, Y. E. et. al. (2016). 2015 American Thyroid Association Management Guidelines for Adult Patients with Thyroid Nodules and Differentiated Thyroid Cancer: The American Thyroid Association Guidelines Task Force on Thyroid Nodules and Differentiated Thyroid Cancer. Thyroid, 26 (1), 1-133. doi: http://doi.org/10.1089/ thy. 2015.0020

[3] Pacini, F., Ito, Y., Luster, M., Pitoia, F., Robinson, B., Wirth, L. (2012). Radioactive iodine-refractory differentiated thyroid cancer: unmet needs and future directions. Expert Review of Endocrinology \& Metabolism, 7 (5), 541-554. doi: http://doi.org/10.1586/eem.12.36

[4] Pfister, D. G., Fagin, J. A. (2008). Refractory Thyroid Cancer: A Paradigm Shift in Treatment Is Not Far Off. Journal of Clinical Oncology, 26 (29), 4701-4704. doi: http://doi.org/10.1200/jco.2008.17.3682

[5] Deandreis, D., Al Ghuzlan, A., Leboulleux, S., Lacroix, L., Garsi, J. P., Talbot, M. et. al. (2010). Do histological, immunohistochemical, and metabolic (radioiodine and fluorodeoxyglucose uptakes) patterns of metastatic thyroid cancer correlate with patient outcome? Endocrine Related Cancer, 18 (1), 159-169. doi: http://doi.org/10.1677/erc-10-0233

[6] Almendro, V., Marusyk, A., Polyak, K. (2013). Cellular Heterogeneity and Molecular Evolution in Cancer. Annual Review of Pathology: Mechanisms of Disease, 8 (1), 277-302. doi: http://doi.org/10.1146/ annurev-pathol-020712-163923

[7] Brychtová, V., Valík, D., Vojtěšek, B. (2018). Variability of Solid Cancer Cell Population and Its Consequences for Cancer Diagnostics and Treatment. Klinicka Onkologie, 31 (2), 2S5-2S13. doi: http://doi.org/ 10.14735/amko20182s5

[8] Le Pennec, S., Konopka, T., Gacquer, D., Fimereli, D., Tarabichi, M., Tomás, G. et. al. (2015). Intratumor heterogeneity and clonal evolution in an aggressive papillary thyroid cancer and matched metastases. Endocrine-Related Cancer, 22 (2), 205-216. doi: http://doi.org/10.1530/erc-14-0351

[9] Ling, V., Chambers, A. F., Harris, J. F., Hill, R. P. (1984). Dynamic heterogeneity and metastasis. Journal of Cellular Physiology, 121 (S3), 99-103. doi: http://doi.org/10.1002/jcp.1041210412 
[10] Kim, H., Piao, Z., Park, C., Chung, W., Park, C. (1998). Clinical significance of clonality in thyroid nodules. British Journal of Surgery, 85 (8), 1125-1128. doi: http://doi.org/10.1046/j.1365-2168.1998.00783.x

[11] Studer, H., Gerber, H., Zbaeren, J., Peter, H. J. (1992). Histomorphological and immunohistochemical evidence that human nodular goiters grow by episodic replication of multiple clusters of thyroid follicular cells. Journal of Clinical Endocrinology \& Metabolism, 75 (4), 1151-1158. doi: http://doi.org/10.1210/ jc.75.4.1151

[12] Mitsutake, N., Iwao, A., Nagai, K., Namba, H., Ohtsuru, A., Saenko, V., Yamashita, S. (2007). Characterization of Side Population in Thyroid Cancer Cell Lines: Cancer Stem-Like Cells Are Enriched Partly But Not Exclusively. Endocrinology, 148 (4), 1797-1803. doi: http://doi.org/10.1210/en.2006-1553

[13] Bozhok, Y., Tavokina, L., Epstein, E. (1996). The new things in diagnostic of thyroid cancer. Optimal combination of morphological and immunocytochemistry research methods of punctious materials. Med Announcer, 138, 40-43.

[14] Zelinskaya, A. (2019). Citokeratin 17 i tireoidna peroksidaza v yakosti imunocitohimichnih markeriv dooperaciynogo prognozuvannya radioiodrezistentnosti ta efektivnosti radioiodterapii papilyarnogo raku shitopodibnoi zalozi. Onkologiya, 21 (1), 31-35.

[15] Latza, U., Niedobitek, G., Schwarting, R., Nekarda, H., Stein, H. (1990). Ber-EP4: new monoclonal antibody which distinguishes epithelia from mesothelial. Journal of Clinical Pathology, 43 (3), 213-219. doi: http://doi.org/10.1136/jcp.43.3.213

\title{
IFLUENCE OF AQUEOUS EXTRACT FROM FEIJOA LEAVES ON THYROID FUNCTION IN RATS WITH EXPERIMENTAL HYPOTHYROIDISM
}

\author{
Alevtyna Kononenko \\ Department of Physiology and Human Anatomy \\ National University of Pharmacy \\ 53 Pushkinskaya str., Kharkiv, Ukraine, 61002 \\ alevtina19820103@gmail.com \\ Vera Kravchenko \\ Department of Physiology and Human Anatomy \\ National University of Pharmacy \\ 53 Pushkinskaya str., Kharkiv, Ukraine, 61002 \\ kvn1965@gmail.com
}

\begin{abstract}
The present work studied the effect of aqueous extract from Feijoa leaves on thyroid function of rats with experimental hypothyroidism. Healthy albino rats weighing between $120 \mathrm{~g}$ and $150 \mathrm{~g}$ were used. The animals were randomly allotted into four groups, each containing eight rats respectively. Three of the groups (II, III and IV), induced with hypothyroidism, were treated by $0.05 \%$ solution of thiamazole with drinking water for 30 days. Control (vehicle) rats were given normal saline. After 13 days hypothyroid groups (III and IV) of rats were treated with aqueous extract from Feijoa leaves at a dose $1.0 \mathrm{ml} / 100 \mathrm{~g}$ of body weight and with Iodomarin 200 (reference drug) at a dose $12 \mu \mathrm{g} / \mathrm{kg}$ daily orally for 21 days. Results obtained from the study showed that the introduction of thiamazole leads to functional changes in the thyroid gland in rats, accompanied by decreasing sings of rectal temperature and level of thyroid hormones. It was found, that treatment with AEFL normalizes serum thyroid hormone levels, increases rectal temperature and reduces the thyroid mass. The investigated extract can be attributed to the regulators of the thyroid hypofunction and is promising for further study of its effectiveness as a thyroid-stimulating agent.
\end{abstract}

Keywords: Feijoa leaves, aqueous extract, hypothyroidism, thiamazole, thyroid hormones. 